\title{
About Climate, Flooding and Underwater Technologies
}

\author{
Oleg Khalidullin* \\ Kazakh National University, named after Al-Farabi, Kazakhstan \\ ${ }^{\star}$ Corresponding author: Oleg Khalidullin, Academician of the Kazakh National University, Kazakhstan; Tel: 87770550099; E-mail: 7115215@mail.ru
}

Received: September 01, 2021; Accepted: September 08, 2021; Published: September 25, 2021

Waters enclosed in reservoirs in front of hydroelectric power plants are also devoid of natural functions - they evaporate from the surface, bloom with algae, but most of it breaks on turbine blades. The destroyed and unused structure of water evaporates into the atmosphere without fulfilling its mission. These vapors are supplemented by all waters taken from nature for irrigation, technological and communal processes. There is more evaporation of such waters than evaporation from biota. The fumes emanating from other than biota can be called artificial. Their volumes, evaporation rate and quality become commensurate with natural fumes or fumes from plants and living organisms. Therefore, the climate is changing and natural disasters occur. Flood spills are a major source of artificial evaporation. How do we feel about rivers? Within the boundaries of cities and towns, we straighten the banks, cover the river beds with concrete and stones. We dump garbage and waste into the water. By their nature, rivers must regularly affect the banks - meandering or interacting with the soil. This is necessary in order to dissolve minerals, organics in water and supply them to animals and plants. Everything dissolved in water is a building material for biota. Water trapped in concrete banks loses its function. It cannot dissolve minerals from the soil in itself and convey it to the consumer. We do the greatest harm to the river by dumping waste and garbage into it. The volumes of discharges raise the river bottom quite strongly. Especially downstream of settlements. It is this circumstance that leads to the overflow of water from the coast during abnormal precipitation, devastating floods and extensive spills. To maintain the carrying capacity of the river bed, it is necessary to periodically clean the bottom of sediments or maintain the historical depth.

The existing technology of deepening the river bottom with dredges and various dredgers is quite metal-consuming, requires significant expenditures of energy, funds and pollution of coastal areas. The main energy required with these methods is spent on holding the agent itself against the current. Considering the possibility of impact on the bottom of the rivers, it is possible to find the moments when gullies and depressions are formed around the sunken ship. Is it possible to use the forces of the movement of the water itself. If we take this principle as a basis, then the simplest special device arises that will clean and deepen the bottom of the river. An ordinary parallelepiped without a bottom and ends, installed at the bottom of the river, will have almost no effect on the flow. Water freely enters one end and exits through the other. But, if a damper is installed inside it to turn the water flow to the bottom, then it becomes possible to displace the bottom particles along the flow. Moving the device downstream, these particles move further.
If the device is moved forward and backward by means of a cable, an underwater longitudinal channel can be obtained. By moving it from coast to other coast, it is possible to move bottom sediments into the transverse shaft. If necessary, the shaft can be lifted to the surface. By reducing the movement of water across the entire width of the river, and by increasing the underwater channel, it is possible to increase the carrying capacity of the entire river. By diverting the main stream away from the collapsing coast, this collapse can be excluded. Thus, influencing the water flows, it becomes possible to change the river bed according to the given parameters. To preserve water for the summer, it is enough to keep the existing ratios of rifts - rapids and reaches - depressions. An increase in these volumes is achieved by a corresponding deepening of the bottom in these places. To increase the speed of the recess, a lead screw can be added to increase the flow of the impact to the bottom. Deepening to the design depth will not allow water to overflow the banks with maximum precipitation. The simplest device can prevent floods. The shown device is primitive in execution, does not require a lot of metal and is not energy intensive. The power to drive the lead screw is hundreds of times less than on dredges. Thus, the manufacture of the device is available to any coastal economy. The idea of impacting the bottom by the current itself goes far beyond a simple deepening. For large river depths, it is possible to manufacture a device with a small power plant, a lead screw, autonomous control, and an underwater life support cabin. A device or Underwater Universal Machine (PUM) has been developed. The uplift and transfer of bottom sediments makes it possible to create new technologies for underwater operations. For example, gold mining. Sorting and disintegration can be carried out directly in the shown closed cavity without bringing the materials to the air. Of course, designers will have to work hard to develop new devices for such work. It becomes possible to search for and recover sunken objects goods without destroying the bottom surface. Conversely, it is possible to remove the bottom layer and transport it to the surface, for example, to obtain sapropel. Repair of underwater structures, such as pipelines, is possible. With completely closed dampers at the ends, it becomes possible to completely stop the movement of water and create an air bell. The version with a lead screw can be used for reservoirs with stagnant or sedentary water - lakes, swamps, seas.

Keywords: Artificial evaporation, Water functions, Deepening of the bottom, New technology, Underwater work.

\section{Citation:}

Khalidullin O (2021) About Climate, Flooding and Underwater Technologies. Geol Earth Mar Sci Volume 3(3): 1-1. 